\title{
RESPOSTAS DAS ESCOLAS AOS ALUNOS SOBREDOTADOS OU COM CAPACIDADES EXCECIONAIS. UM BREVE OLHAR SOBRE OS OLHARES DOS AVALIADORES EXTERNOS
}

\author{
Augusto Patrício Lima ROCHA ${ }^{1}$ \\ Sófia Cláudia Oliveira SOUSA ${ }^{2}$
}

RESUMO: No ano 2012-2013, a Inspeção-Geral de Educação e Ciência (IGEC) através do programa Avaliação Externa de Escola avaliou 122 agrupamentos de escolas e 22 escolas não agrupadas. Para cada unidade educativa é produzido um relatório que se encontra publicitado na página web da IGEC. Em cada relatório a equipa de avaliação faz uma apreciação do funcionamento da organização educativa avaliada de acordo com nove campos de análise. Estes campos integram-se em três domínios (Resultados; Prestação do Serviço Educativo e Liderança e Gestão). Cada domínio é classificado de acordo com uma escala com cinco níveis (excelente, muito bom, bom, suficiente e insuficiente). Na última secção de cada relatório, refere-se os principais pontos fortes, bem como às áreas de melhoria. Com a finalidade de se compreender os principais dispositivos educativos existentes nas escolas singulares e agrupamentos, bem como a qualidade e natureza das respostas educativas prestadas aos alunos sobredotados, analisámos o conteúdo dos 59 relatórios da Área de Inspeção Territorial Norte. Em função dos resultados obtidos concluímos que existe um longo caminho a percorrer para que a escola seja na sua plenitude uma organização inclusiva.

PALAVRAS-CHAVE: Sobredotação. Alunos com capacidades excecionais. Inclusão. Diferenciação pedagógica. Avaliação externa de escolas.

\section{Introdução}

Não obstante a Constituição da República Portuguesa estabelecer no seu artigo 74. ' que "todos têm direito ao ensino com garantia do direito à igualdade de oportunidades de acesso e êxito escolar" (PORTUGAL, 1976) e de Portugal ser subscritor de recomendações internacionais relativamente à educação das crianças mais capazes, designadamente a recomendação $\mathrm{n}^{\mathrm{o}} 1248$ do Conselho da Europa ou a Declaração de Salamanca, também é nossa fundada convicção que existe um longo caminho a percorrer para que a escola seja na sua plenitude uma organização inclusiva.

A origem da ideia de inclusão, ligada à noção de "uma educação para todos" situa-se na Conferência da UNESCO (1990) realizada em Jomtien (Tailândia) sendo consensualmente adotada e generalizada como um princípio e política educativa, quatro

\footnotetext{
${ }^{1}$ Inspetor do IGEC - Inspeção-Geral de Educação e Ciência de Portugal. Pós-graduado em Educação Especial e em Inspeção Escolar. Lisboa - Portugal. 1350-346 - patriciorocha@ msn.com.

${ }_{2}$ Psicóloga do Agrupamento de Escolas de Portel. Portel - Évora - Portugal. 7220-401 sofiaclaudiasousa@gmail.com.
} 
anos depois, na conferência de Salamanca. A escola inclusiva não é só uma escola que cultiva a diversidade, mas também a que se adapta a todas as crianças e jovens, independentemente das suas condições físicas, intelectuais, linguísticas ou outras. Normalmente, o conceito de inclusão é trazido à colação nas abordagens relacionadas com crianças e jovens que se encontram em situação de deficiência. Porém, esta perspectiva é bastante redutora, porquanto internacionalmente a inclusão é vista de forma cada vez mais ampla, como uma reforma que apoia e acolhe a diversidade entre todos os alunos (UNESCO, 2001). Uma escola e uma sociedade que assumam a heterogeneidade enriquecem-se com a diferença e tornam-se mais justas ao responderem às especificidades de cada sujeito. Responder às necessidades de cada criança/aluno implica, entre outras coisas, estar receptivo à ideia que no grupo de alunos/crianças que frequentam a escola regular existem não só alunos com dificuldades de aprendizagens, mas também alguns com capacidades excecionais e talentosos.

Ora, o principal enfoque deste trabalho são as crianças/alunos que a literatura designa de sobredotados, talentosos ou com capacidades excecionais. É que, resulta para nós evidente, que uma escola só será verdadeiramente inclusiva e democrática se der respostas adequadas e ajustadas a este tipo de alunos.

Até aos anos 60, predominou um enfoque redutor das elevadas capacidades e o desempenho nas provas para determinar o quociente de inteligência (Q.I.) foi o principal indicador da existência de capacidades excecionais ou de sobredotação. Nesta linha, considerava-se que o individuo sobredotado deveria apresentar um Q.I. igual ou superior a 140 , correspondendo a cerca de $2 \%$ dos sujeitos com os resultados mais elevados em provas de inteligência.

Atualmente, apesar de não existir uma definição única de sobredotação, aceita-se a multidimensionalidade deste constructo, daí decorrendo dificuldades não só na identificação, mas também da intervenção educativa junto dos alunos sobredotados ou com capacidades excecionais.

Concordamos com Novaes (1979) quando este autor, a propósito da existência de alunos/crianças sobredotados afirma:

[...] partindo-se do princípio de que há possibilidade de crianças superdotadas e talentosas existirem em todas as camadas sociais, grupos étnicos e raciais, são válidos os esforços realizados a nível comunitário para promover o atendimento de suas necessidades psicosocioeducacionais. (NOVAES, 1979, p.11). 
Resulta para nós claro, tal como defende Winner (1999, p.11), que “[...] nenhuma sociedade se pode dar ao luxo de ignorar os seus membros mais dotados, e todos devem pensar seriamente em como encorajar e educar esse talento". Neste sentido, apesar da sobredotação configurar-se como um permanente desafio para os professores, pais e sociedade, também importa ter presente na esteira de Serra (2000, p.149) que "[...] a escola é muitas vezes fator inibidor do aparecimento ou desenvolvimento das potencialidades dos alunos".

\section{Conceito e modelos explicativos}

A delimitação do conceito de sobredotação não é tarefa fácil, pois estamos perante um constructo complexo e multidimensional. Neste sentido, para além das componentes cognitivas e académicas é necessário considerar a motivação, a criatividade, talentos especiais, bem como caraterísticas pessoais. Nesta linha, a sobredotação emerge, mais como um perfil de competência do que como um índice ou traço exclusivo (CASTELLÓ; GENOVARD, 1999). Daqui resulta que os processos de avaliação não são fáceis, devendo-se ter em consideração, para além do QI, vários critérios na elegibilidade destes alunos.

Não obstante exista ainda uma falta de consenso quanto à questão da delimitação terminológica do conceito de sobredotação, há atualmente uma consciência não só da existência dos sobredotados, mas também que e necessário oferecer-lhes uma educação que lhes permita desenvolver todo o seu potencial. Ademais, verifica-se a adoção na literatura de investigação o emprego de um vasto conjunto de termos (e.g., talento, génio) para designar jovens que manifestem qualquer forma de sobredotação.

$\mathrm{Na}$ grande maioria dos países europeus, os termos mais comuns nas definições nacionais são "sobredotados" e "talentosos" (ou os seus equivalentes nas outras línguas), utilizados separados ou conjuntamente. Contudo, é de salientar que no Reino Unido é feita uma distinção entre eles: o termo "gifted" (sobredotado) é empregue num contexto "intelectual" ou "académico", enquanto o termo "talented" (talentoso) é mais do foro das artes e do desporto. Certos países, nos quais se inclui Portugal, não empregam estes termos, avançando expressões como "jovem de grande capacidade potencial" (Comunidade Francófona da Bélgica), "jovens de grande capacidade" 
(Comunidade Flamenga da Bélgica), "crianças intelectualmente precoces" (Franca) ou "alunos com grandes capacidades intelectuais" (Espanha). Na Roménia, os termos utilizados nos documentos oficiais são "alunos capazes de grandes desempenhos" $\mathrm{e}$ “alunos com capacidades excecionais". Em Portugal, com a recente publicação do despacho normativo n. ${ }^{\circ}$ 24-A/2012, de 6/12, os termos utilizados para os nomear são: “[...] aluno que revele capacidade de aprendizagem excecional e um adequado grau de maturidade." (PORTUGAL, 2012).

Com base nas áreas contidas na definição federal americana de aluno sobredotado ou talentoso, Johnsen (2004, p.388) avança que as crianças sobredotadas têm um potencial de alta performance:

[...] gifted and talented' when used in respect to students, children, or youth means students, children, or youth who give evidence of high performance capability in areas such as intellectual, creative, artistic, or leadership capacity, or in specific academic fields, and who require services or activities not ordinarily provided by the school in order to fully develop such capabilities.

Nesta linha, as crianças sobredotada ou talentosa evidenciam elevadas capacidades intelectuais, criativas ou artísticas, possuem uma capacidade de liderança fora do comum e distinguem-se numa determinada área académica.

Relacionando a sobredotação com as inteligências múltiplas, Falcão (1992, p.70) antecipa a seguinte definição:

[...] criança sobredotada é aquela que possui um potencial humano de nível superior e frequência constante em qualquer uma, ou mais, das áreas operacionais das I. M. (Inteligências Múltiplas), permitindo prognosticar, se fornecidas adequadas oportunidades de desenvolvimento, um elevado grau de competência específica, quer na solução de problemas, quer na criação de produtos.

Os modelos explicativos de sobredotação ancoram-se nas abordagens conceptuais em torno da inteligência humana acentuando a dimensão multidimensional e qualitativa. Atualmente, existem diferentes modelos explicativos deste conceito, sendo de destacar a Teoria Triárquica da Inteligência (STERNBERG, 1985), o Modelo Diferenciado de Sobredotação e Talento (GAGNÉ, 1985, 2004), a Teoria das Inteligências Múltiplas (GARDNER, 1983), a Conceção de Sobredotação dos Três Anéis (RENZULLI, 1986) e o Modelo Multifactorial da Sobredotação (MÖNKS, 1988). 
Na Teoria Triárquica da Inteligência de Sternberg (1985), o enfoque dirige-se mais nos processos envolvidos na tarefa realizada pelo indivíduo, do que no produto final. De acordo com esta teoria, a inteligência estrutura-se em três partes interrelacionadas, existindo diversas componentes da sobredotação e vários tipos de sobredotação. A sobredotação emerge como um constructo plural. Segundo esta teoria existem três tipos de sobredotação intelectual: analítica, criativa e prática. O indivíduo sobredotado poderá evidenciar-se apenas num, em dois, ou nos três domínios em simultâneo.

De acordo com Modelo Diferenciado de Sobredotação e Talento apresentado por Gagné (1985, 2004), a sobredotação é considerada como uma aptidão natural, ou seja, uma herança genética, enquanto os talentos são resultado de uma interação de predisposições naturais com os contextos físicos e sociais que envolvem o indivíduo. Este autor considera que o desenvolvimento de talentos é fortemente influenciado pela aprendizagem e pela prática. Gagné (1985) propõe que a sobredotação se refere à existência e uso de habilidades naturais (ou aptidões), materializadas de maneira espontânea em pelo menos um domínio da atividade humana. Por outro lado, o conceito talento designa um nível superior de habilidades (ou competências) que são desenvolvidas a partir do treino regular e domínio de conhecimento em pelo menos uma área da atividade humana (e.g., académica, artística, desportiva e social). Este modelo distingue quatro domínios de aptidão/habilidades naturais: intelectual, criativo, sócioafectivo e sensório-motor. As capacidades naturais emergem como "matéria-prima" e na linha de Gagné e Guenther (2010, p.17) “[...] talento implica necessariamente a presença de capacidade natural acima da média e não se pode tornar talentoso sem primeiro ser dotado de capacidade". Contudo, nem todas as predisposições ou capacidades naturais elevadas se desenvolvem em talentos, já que o seu desenvolvimento pode ser prejudicado pela ausência de estimulação no ambiente.

Na sua Teoria das Inteligências Múltiplas, Gardner (1983) apresenta uma abordagem multidimensional, ampla e pragmática da inteligência. A inteligência será constituída por múltiplas habilidades, distintas entre si. Apesar de diferenciadas, as distintas inteligências são interativas. A sobredotação pode emergir para uma das sete formas de inteligência que Gardner (1983) postula: lógico-matemática, linguística, espacial, musical, corporal-cinestésica, interpessoal e intrapessoal. Posteriormente, o autor inclui nesta classificação um oitavo tipo de inteligência: a naturalista, apontando ainda a possibilidade de mais duas: espiritual e existencial (GARDNER, 1999). 
Oliveira (2007, p.20) destaca os trabalhos de Joseph Renzulli como sendo uma referência na atualidade, na abordagem da temática da sobredotação. A Conceção de Sobredotação dos Três Anéis de Renzulli (1986) (OLIVEIRA, 2007) compreende a sobredotação como resultado da interação de três componentes: habilidade intelectual superior, criatividade e envolvimento na tarefa. As habilidades podem ser gerais (raciocínio numérico, raciocínio abstrato, relações espaciais, fluência verbal, memória) ou mais específicas (e.g. matemática, música, química, dança) e a este nível podem manifestar-se pela aplicação de várias combinações das habilidades superiores gerais a uma ou mais áreas especializadas de conhecimento ou de realização humana (e.g. artes plásticas, liderança, fotografia). Nenhum destes componentes, por si só, será suficiente para a expressão da sobredotação. É a interação entre os três fatores (inteligência, motivação, criatividade) que permite a realização criativa-produtiva (OLIVEIRA, 2007).

Mönks $(1988$, 1992) no seu Modelo Multifactorial da Sobredotação, amplia o modelo Modelo dos Três Anéis de Renzulli (1986) considerando a natureza interativa do desenvolvimento humano introduzindo a escola, a família e os pares, como fatores determinantes. Neste sentido o autor complementa a conceção anterior com uma perspetiva desenvolvimental. Neste modelo, Mönks $(1988,1992)$ enfatiza as interações que o indivíduo estabelece com o meio ao longo do seu percurso desenvolvimental para a manifestação da sobredotação. Assim, considera-se que sobredotação inclui dimensões psicossociais complementares da inteligência ou das habilidades cognitivas dos indivíduos sobredotados (OLIVEIRA, 2007).

\section{Respostas educativas para os alunos sobredotados}

Se é certo que trabalhar com alunos sobredotados constitui um interessante desafio à função docente, também resulta claro que sem incentivos e resposta educativa ajustados, estes alunos correm o risco de fracasso escolar. Na realidade, a investigação científica não só revela que o sucesso destes alunos depende das suas experiências educativas, como também apresenta múltiplas medidas de formato e objetivos diversos. Porém, de entre tais respostas educativas, as mais referenciadas incluem a aceleração, o agrupamento e os programas de enriquecimento (grifo nosso). 
A aceleração escolar integra métodos que permitem reduzir o tempo de permanência dos alunos no sistema escolar normal, através de um ritmo mais rápido de aprendizagem, de acordo com as suas necessidades educativas (ACEREDA; SASTRE, 1998). Normalmente a aceleração tem em comum a oferta do mesmo material, mas a um ritmo mais rápido e/ou mais cedo para os alunos sobredotados ou com capacidades excecionais.

Southern, Jones e Stanley (1993, p.387) realçam três pressupostos relacionados com a adoção de medidas de aceleração:

(i) os alunos sobredotados apresentam uma maior rapidez nas suas aprendizagens relativamente aos seus pares (ii) muitas das necessidades destes alunos poderão ser atendidas através de uma aceleração do ritmo de ensino ou do "salto" de classe escolar e (iii) o conteúdo curricular das classes mais avançadas é, em regra, apropriado e mais motivante para os alunos com aprendizagens excecionais.

Uma das formas mais comum de aceleração consiste no "salto" de classe escolar. Contudo, é de realçar que existem diversos procedimentos para além do salto de classe que permitem atingir esta mesma finalidade. Ao longo do percurso escolar, a primeira possibilidade de aceleração consiste na entrada antecipada na escolaridade. Neste sentido, a criança que demonstra maturidade excecional em termos cognitivos e sociais ingressa na escola e por esta via inicia a sua escolarização formal antes da idade legalmente instituída.

Um outro procedimento de aceleração consiste no "salto" de classe, ou seja, na eliminação de um ano de escolaridade ou período na escola, permitindo que o aluno avance um ou mais anos escolares no sistema educativo. Vários estudos demonstram que, em termos gerais, os alunos que beneficiam desta medida mostram um nível de ajustamento social, académico e vocacional superior, ou equivalente, ao dos alunos igualmente sobredotados que não foram acelerados (KIRK; GALLAGHER, 2000).

Uma alternativa análoga ao "salto" de classe é procedimento designado telescoping que consiste na condensação de anos de escolaridade. Através desta medida o aluno sobredotado percorre o currículo normal num período mais curto de tempo. Trata-se, neste caso, de um tipo de aceleração curricular, na qual o aluno pode aprender ao seu ritmo mais matéria em menos tempo. 
As práticas de agrupamento, em termos gerais, consistem em juntar os alunos em pequenos grupos, turmas ou escolas, para um ensino conjunto, de acordo com o seu nível de habilidade ou preparação académica, em horário parcial ou a tempo inteiro (ACEREDA; SASTRE, 1998; MCCOACH; O’CONNELL; LEVITT, 2006). Existem diversas modalidades de agrupamento, sendo que estes podem ser constituídos de forma permanente ou temporária. Entre as várias alternativas e opções educativas no atendimento aos alunos com capacidades elevadas, o agrupamento tem sido a estratégia mais controversa e contestada ao longo dos anos, sobretudo quando implica a formação de turmas ou escolas especiais, fora dos contextos educativos regulares.

Não obstante algumas limitações que têm sido apontadas, muitos autores elegem os programas de enriquecimento como a medida educativa de apoio aos alunos sobredotados mais frequente (ACEREDA; SASTRE, 1998; RENZULLI; REIS, 2003). Uma das críticas centra-se na natureza dos objetivos dos citados programas, os quais valorizam essencialmente as áreas cognitivas, dando-se reduzida importância à definição de objetivos e iniciativas voltadas para o desenvolvimento social e emocional ou para o sentido estético.

O enriquecimento consiste na implementação de um programa qualitativamente diferente do currículo regular, com o objetivo de aprofundar e diversificar as aprendizagens dos alunos (MAKER; NIELSON, 1995). Estas alterações ou ampliações podem aplicar-se no conteúdo a abordar ou nas metodologias de ensino adotadas e devem basear-se nas características dos alunos aos quais se destinam (ACEREDA; SASTRE, 1998). Desta forma, os programas de enriquecimento consistem em medidas educativas especiais que permitem ampliar e diversificar as aprendizagens dos alunos em função dos seus interesses, aptidões e necessidades educativas (SCHIEVER; MAKER, 1997).

\section{Respostas educativas e legislação em Portugal}

Apenas nos anos 80, algumas associações de pais e de professores começam a suscitar o debate sobre a sobredotação com a finalidade de sensibilizar as autoridades e a sociedade em geral. Não obstante a partir desta data se realizarem várias conferências, palestras, encontros, editado brochuras e livros e cursos de formação para docentes e ainda alguma investigação a tomar forma, o apoio aos alunos sobredotados ou talentosos em contexto escolar não se encontra firmado. Ao longo das últimas duas 
décadas têm surgido alguns programas de enriquecimento dentro e fora das organizações educativas, bem como programas centrados no desenvolvimento de competências cognitivas e criativas ou de relacionamento interpessoal. Contudo, a implementação e abrangência desses programas não só é diminuto, como, na maioria dos casos, não se conhece com rigor o impacto dos mesmos nas crianças e alunos que a eles foram sujeitos.

Assim, atualmente, pode afirmar-se que em Portugal não só as respostas educativas às crianças e alunos sobredotados são débeis, como é parca a legislação na área do atendimento destas crianças e alunos. Desde logo é de realçar que não se utiliza este termo na legislação em vigor, mas sim capacidade de aprendizagem excecional.

A atual legislação portuguesa apenas contempla a "aceleração" ou o "salto de ano", mas cujo âmbito se circunscreve apenas ao ensino básico. Esta medida encontrase plasmada no artigo $25 .^{\circ}$ do despacho normativo n. ${ }^{\circ}$ 24-A/2012, de 6/12 (PORTUGAL, 2012) e sob a designação de casos especiais.

Até à aprovação desde diploma também vigorava o Despacho Normativo n. ${ }^{\circ} 50$ de 2005 de 9 de novembro (PORTUGAL, 2011). Este último diploma, entretanto revogado, previa a aplicação dos designados "planos de desenvolvimento" a alunos que manifestassem capacidades excecionais de aprendizagem, podendo esses planos integrar as seguintes modalidades de apoio (a) pedagogia diferenciada na sala de aula; (b) programas de tutoria para apoio a estratégias de estudo orientação e aconselhamento do aluno; e, (c) atividades de enriquecimento em qualquer momento do ano letivo ou no início de um novo ciclo (PORTUGAL, 2005). Do exposto, pode-se afirmar ter-se verificado uma regressão legislativa, porquanto, atualmente existe um certo vazio normativo em relação à implementação de medidas curriculares aos alunos que revelem capacidades de aprendizagem excecionais.

O recente Decreto-Lei 3/2008 (PORTUGAL, 2008) que enquadra a Educação Especial circunscreve-a:

[...] aos alunos com limitações significativas ao nível da atividade e participação num ou vários domínios da sua vida, decorrentes de alterações funcionais e estruturais de carácter permanente, resultando dificuldades continuadas ao nível da comunicação, da aprendizagem, do relacionamento interpessoal e da participação social. (PORTUGAL, 2008). 
Concluindo-se que o âmbito deste decreto-lei não se aplica naturalmente aos alunos sobredotados.

\section{Percurso metodológico}

Desde 2006, a Inspeção-Geral da Educação, atualmente Inspeção-Geral da Educação e Ciência (IGEC) tem em desenvolvimento um programa de avaliação externa das escolas. O foco deste artigo incide sobre a análise efetuada aos Relatórios de Avaliação Externa das Escolas produzidos no ano 2012-2013 e relativos à área Territorial de Inspeção Norte. Optamos por circunscrever a análise ao universo de escolas não agrupadas e agrupadas.

Em termos metodológicos, recorreu-se à análise documental, articulando a abordagem quantitativa das variáveis objetivas com um enfoque qualitativointerpretativo do conteúdo dos Relatórios. Apesar de se efetuar uma leitura global de todos os relatórios, selecionou-se para análise mais aprofundada apenas o domínio da Prestação do Serviço Educativo. De acordo com Tuckman (2002) e Quivy e Campenhoudt (2003), a análise documental constitui um dos três grandes grupos de métodos de recolha de dados que se podem utilizar como fontes de informação nas investigações qualitativas. Ora, tendo em consideração os objetivos delineados, enveredámos por um estudo de natureza mista, sendo a análise dos relatórios produzidos pelas equipas de avaliação externa no âmbito da atividade avaliação externa de escolas, o método de pesquisa central. Os relatórios de inspeções escolares são na linha de Bell (1993) fontes inadvertidas.

Num primeiro momento, os dados de caracterização das escolas, bem como os resultados de avaliação obtidos neste domínio, foram inseridos informaticamente no programa SPSS, com o objetivo de identificar algumas regularidades estatísticas e de aferir a pertinência de algumas correlações significativas entre variáveis. Num momento posterior, procedeu-se à análise de conteúdo categorial do domínio referido, procurando extrair dos textos os sentidos dominantes de fortaleza e de fragilidade no campo de análise Práticas Educativas.

Os pontos fortes e as áreas de melhoria existentes na totalidade dos 59 relatórios analisados foram separados em unidades relevantes e significativas em função do tema abordado. As categorias analíticas emergiram no decurso da análise dos relatórios. Para o cálculo dos testes Qui-Quadrado, Levene, T ou coeficiente de correlação de Spearman 
transformaram algumas variáveis qualitativas em variáveis numéricas, conforme quadro a seguir.

Quadro 1 - Transformação de variáveis

\begin{tabular}{|c|c|c|}
\hline Variável & Categorias & Transformação \\
\hline \multirow{2}{*}{$\begin{array}{c}\text { Diferenciação } \\
\text { pedagógica }\end{array}$} & É generalizável/sistemática ou consistente & 3 \\
\cline { 2 - 3 } & Não é generalizável/sistemática ou consistente & 2 \\
\hline \multirow{2}{*}{ Inclusão } & As políticas ou cultura de inclusão são ponto \\
forte & As políticas ou a inclusão não emerge como \\
\cline { 2 - 3 } & ponto forte & 2 \\
\hline \multirow{2}{*}{ Classificação } & Muito Bom & 2 \\
\cline { 2 - 3 } & Inferior a Muito Bom & 1 \\
\hline
\end{tabular}

Fonte: Elaborado pelos autores.

Já para a análise de conteúdo do campo de análise Práticas de Ensino do domínio Prestação do Serviço Educativo foram definidas cinco categorias analíticas conforme o quadro.

Quadro 2 - Categorias analíticas utilizadas na análise de conteúdo

\section{Categorias analíticas}

Não há adequação de práticas/atividades/estratégicas adequadas às capacidades e aos ritmos das crianças e dos alunos

Desenvolve de forma não generalizada/abrangente/consolidada (i) diferenciação pedagógica e/ou (ii) iniciativas/atividades/estratégias adequadas às capacidades e ritmos

Desenvolve práticas/atividades/estratégias educativas e do ensino adequadas às capacidades e aos ritmos das crianças e dos alunos

A oferta educativa/formativa adequada às capacidades e ritmos das crianças e dos alunos

Desenvolve práticas de diferenciação pedagógica de forma consistente/generalizada Fonte: Elaborado pelos autores. 


\section{Principais objetivos do estudo}

Sendo certo que o enfoque do programa Avaliação Externa de Escolas (AEE), não é a avaliação de programas centrado nas crianças e alunos com capacidades excecionais nem no serviço educativo prestado a estes alunos, também é verdade que ao constituir a prestação do serviço educativo um domínio estratégico de qualquer instituição educativa e do próprio programa da AEE é natural que se tenha em conta na avaliação deste domínio a natureza e a qualidade das respostas educativas para todas as crianças e alunos que frequentam a escola, quer sejam portadores de deficiência ou não, quer tenham dificuldades de aprendizagem ou seja sobredotados, talentosos ou tenham capacidades excecionais, isto é, a todos. Ora, foi com base nesta realidade e no conhecimento de que um campo de análise deste domínio se prende com a adequação das atividades educativas e do ensino às capacidades e aos ritmos de aprendizagem das crianças e dos alunos, que decidimos investigar o retrato dado pelos relatórios de avaliação externa em relação à temática da sobredotação.

Neste sentido, com a finalidade de se compreender os principais dispositivos educativos existentes nas nossas escolas, bem como a qualidade e a natureza das respostas educativas prestadas a estas crianças/alunos e ancorados numa metodologia de natureza mista, fomos analisar o conteúdo dos relatórios de avaliação externa de todos os agrupamentos de escolas e escolas não agrupadas da região norte avaliados em 20122013.

Assim, o nosso trabalho empírico foi norteado pelas seguintes questões de partida:

- Que vertentes da ação educativa dirigida para crianças e alunos que revelam capacidades excecionais são avaliadas na atividade avaliação externa de escolas?

- Quais as principais medidas educativas para alunos sobredotados e talentosos são oferecidas pelas escolas avaliadas?

- As escolas avaliadas desenvolvem diferenciação pedagógica adequada aos alunos com capacidades excecionais?

- Que fragilidades e pontos fortes relacionados com alunos sobredotados são relatados na avaliação externa de escolas?

- Na maioria dos agrupamentos avaliados, a educação prestada aos alunos que revelam capacidades excecionais emerge como um ponto forte ou como área de melhoria? 
- Haverá relação entre as escolas consideradas inclusivas e as perspetivadas como menos inclusivas?

Assim, definimos os seguintes objetivos específicos:

- Averiguar os principais aspetos da educação dos alunos com capacidades excecionais vertidos nos relatórios da avaliação externa de escolas.

- Descrever os pontos fortes e as áreas de melhoria relacionados com o serviço educativo prestado aos alunos e registados nos relatórios da atividade avaliação externa de escolas.

\section{Amostra}

O programa Avaliação Externa das Escolas (AEE) abrangeu, em 2012-2013, no continente, 122 agrupamentos de escolas e 22 escolas não agrupadas, com distribuição regional conforme Quadro 3.

Quadro 3 - Tipologia das unidades de gestão avaliadas em 2012-2012 e sua distribuição no continente

\begin{tabular}{|c|c|c|c|}
\hline $\begin{array}{c}\text { Área de inspeção } \\
\text { territorial }\end{array}$ & \multicolumn{2}{|c|}{ Tipologia da unidade de gestão } & \multirow{2}{*}{ Totais (N. ${ }^{\mathbf{o}}$ ) } \\
\cline { 2 - 3 } & Agrupamentos & $\begin{array}{c}\text { Escolas não } \\
\text { Agrupadas }\end{array}$ & \\
\hline Norte & 49 & 10 & $\mathbf{5 9}$ \\
\hline Centro & 25 & 3 & $\mathbf{2 8}$ \\
\hline Lisboa e Vale do Tejo & 27 & 8 & $\mathbf{3 5}$ \\
\hline Alentejo e Algarve & 21 & 1 & $\mathbf{2 2}$ \\
\hline TOTAIS & 122 & 22 & $\mathbf{1 4 4}$ \\
\hline
\end{tabular}

Fonte: Elaborado pelos autores.

Selecionámos como amostra todos os agrupamentos e escolas não agrupadas avaliados nesse período, na área territorial de inspeção norte $(n=59)$.

\section{Resultados obtidos}

No Quadro 4 resume-se algumas variáveis relativas aos alunos/crianças que frequentam as unidades de gestão (agrupamentos de escolas e escolas não agrupadas) da amostra. 
Quadro 4 - Número de alunos que frequentavam as unidades de gestão da amostra

\begin{tabular}{|l|c|c|c|c|c|c|}
\hline \multirow{2}{*}{$\begin{array}{c}\text { Tipologia da unidade } \\
\text { de gestão }\end{array}$} & $\bullet^{\circ}$ & \multicolumn{5}{|c|}{$\begin{array}{c}\text { Crianças/alunos/formandos que frequentam as } \\
\text { unidades educativas }\end{array}$} \\
\cline { 3 - 7 } & & $\begin{array}{c}\mathbf{N .}^{\mathbf{0}} \\
\text { total }\end{array}$ & Média & Máximo & Mínimo & $\begin{array}{c}\text { Desvio } \\
\text { Padrão }\end{array}$ \\
\hline Agrupamentos & 9 & 67168 & 1399 & 3416 & 290 & 669,67 \\
\hline Escolas Profissionais & 3 & 513 & 171 & 244 & 59 & 98,4 \\
\hline Escolas Secundárias & 6 & 6405 & 1068 & 1394 & 662 & 293,06 \\
\hline $\begin{array}{l}\text { Escolas Básicas } \\
\text { Integradas }\end{array}$ & 1 & 148 & 148 & 148 & 148 & 0 \\
\hline TOTAIS & $\mathbf{9}$ & $\mathbf{7 4 2 3 4}$ & $\mathbf{1 2 5 8 , 2 0}$ & $\mathbf{3 4 1 6}$ & $\mathbf{5 9}$ & $\mathbf{6 8 9 , 7 3}$ \\
\hline
\end{tabular}

Fonte: Elaborado pelos autores.

Os 59 agrupamentos e escolas não agrupadas da amostra eram frequentados por 74234 crianças/alunos/formandos. A média do número de crianças/alunos/formandos que frequentavam os 49 agrupamentos é de 1399, enquanto que nas escolas não agrupadas e secundárias esse número era de 1068, verificando-se, como seria de esperar, que as escolas singulares/não agrupadas são frequentadas por menos alunos que os agrupamentos de escolas.

No gráfico 1 representa-se a percentagem de classificações atribuídas no domínio Prestação do Serviço Educativo para a totalidade das escolas da amostra.

Gráfico 1- Classificações no domínio Prestação do Serviço Educativo para a totalidade da amostra $(n=59)$

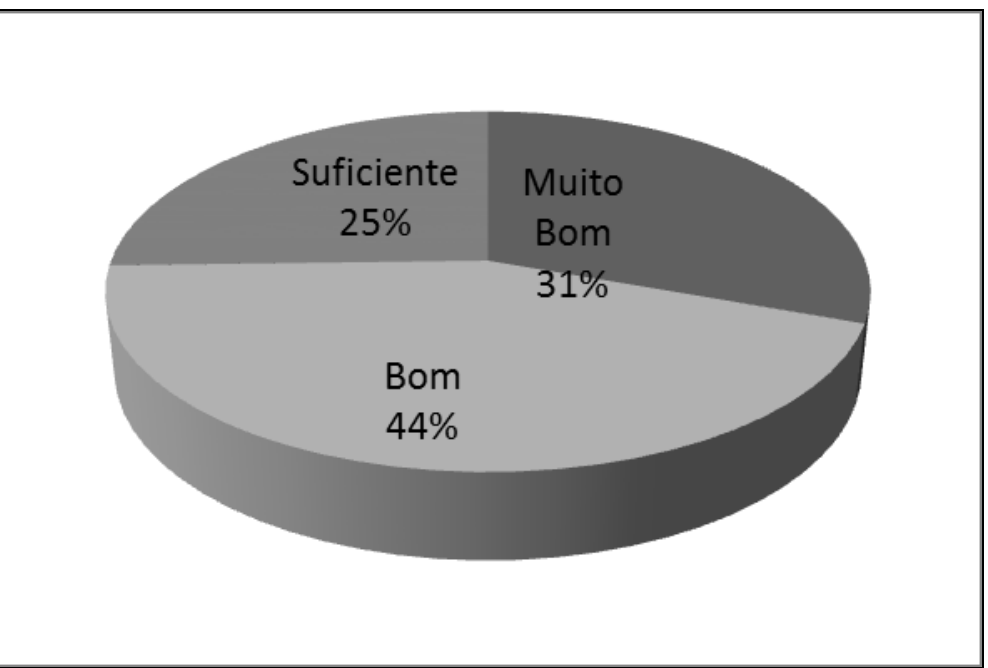

Fonte: Elaborado pelos autores. 
Em relação à classificação atribuída pelas equipas de avaliação no domínio Prestação do Serviço Educativo observamos que a classificação de Bom da escala classificativa é predominante, seguindo-se a classificação de Muito Bom (Gráfico 1).

Nenhuma escola avaliada apresenta a classificação de insuficiente ou excelente no domínio da prestação do serviço educativo. Verificou-se que não existe correlação estatisticamente significativa entre a classificação do domínio prestação do serviço educativo e a tipologia da unidade de gestão (escola/agrupamento) [Teste Levene $\mathrm{F}=$ 193,4; Significância=0,17; teste T Significância (bilateral) $=0,529]$.

Com base na análise dos pontos fortes e das áreas de melhoria registados nos relatórios da nossa amostra $(n=59)$, conclui-se que a maioria dos agrupamentos e escolas singulares apresenta mais pontos fortes do que áreas de melhoria. Na totalidade dos 59 relatórios identificámos 307 pontos fortes, a que corresponde uma média de 5,5 pontos fortes por agrupamento/escola. O número de pontos fortes em cada agrupamento/escola varia entre 3 (mínimo) e 8 (máximo). Nesses mesmos relatórios encontram-se registadas 279 asserções relacionadas com áreas de melhoria, a que corresponde uma média de 5,0 áreas de melhoria por relatório. O número de asserções relacionadas com áreas de melhoria, por agrupamento, varia entre 3 (mínimo) e 8 (máximo).

Verificamos que as políticas e/ou cultura de inclusão são apontadas como um ponto forte em 10 agrupamentos, ou seja, em $17 \%$ das unidades de gestão da amostra. Para além das asserções relacionadas com inclusão, constatámos a presença de três pontos fortes relacionados com a temática em estudo, que são: (i) As práticas diferenciadas (ii) as práticas de articulação vertical, que possibilitam respostas educativas adequadas às características dos grupos e das turmas e aos ritmos de aprendizagem das crianças e alunos e o (iii) princípio da diferenciação pedagógica.

Já em relação às áreas de melhoria, verificámos que só um relatório apresenta áreas de melhoria relacionadas com a temática em estudo. Curiosamente, nesse relatório apresentam-se duas áreas de melhoria relacionadas com a problemática em investigação, nomeadamente: (i) A generalização das práticas de diferenciação pedagógica na sala de aula e (ii) a criação de dispositivos de identificação e apoio aos alunos com capacidades excecionais.

Também se realizou uma análise de conteúdo do domínio Prestação do Serviço Educativo, bem como do campo de análise Práticas de Ensino. O Quadro 5 sintetiza a frequência das principais asserções relacionadas com os aspetos positivos / aspetos 
conseguidos e pontos fracos no âmbito da diferenciação pedagógicas, da adequação de práticas/iniciativas as capacidades e às capacidades e aos ritmos de aprendizagem das crianças e dos alunos. De realçar, que as duas últimas asserções ínsitas no Quadro 5, ou seja, (i) Não desenvolve iniciativas/atividades que potenciem o desenvolvimento das aprendizagens de alunos com capacidades excecionais e (ii) desenvolve iniciativas/atividades que potenciem o desenvolvimento das aprendizagens de alunos com capacidades excecionais encontram-se registadas nos relatórios conjuntamente com uma das cinco primeiras. Assim, não obstante em 13,5\% das unidades de gestão da amostra se encontrar registado explicitamente que não desenvolvem iniciativas/atividades que potenciem o desenvolvimento das aprendizagens de alunos com capacidades excecionais, também resulta claro que só em $20,3 \%$ dos relatórios se refere claramente que há desenvolvimento de práticas de diferenciação pedagógica de forma consistente/generalizada. Contudo, mesmo os relatórios em que se refere que a diferenciação pedagógica é uma prática generalizada são omissos em relação aos alunos sobredotados ou com capacidades de aprendizagem excecional. Porém, existe um relatório em que se refere explicitamente que a escola desenvolve práticas educativas para estes alunos/crianças.

Verificou-se que existe associação estatisticamente significativa entre a variável classificação atribuída no domínio Prestação do Serviço Prestado e a variável diferenciação pedagógica (valor do teste Qui-Quadrado de Pearson foi de 14,065 com um nível de significância inferior a 0,0005. O coeficiente de correlação Spearman foi de 0,488, para um nível de significância de 0,01).

Quadro 5 - Frequência das asserções do âmbito da adequação das atividades educativas e do ensino às capacidades e aos ritmos das crianças e dos alunos ínsitas no corpo dos 59 relatórios de AEE

\begin{tabular}{|l|c|}
\hline \multicolumn{1}{|c|}{ Categorização das asserções } & Frequência (n) \\
\hline $\begin{array}{l}\text { Não há adequação de práticas/atividades/estratégicas adequadas às } \\
\text { capacidades e aos ritmos das crianças e dos alunos }\end{array}$ & 2 \\
\hline $\begin{array}{l}\text { Desenvolve de forma não generalizada/abrangente/consolidada (i) } \\
\text { diferenciação pedagógica e/ou (ii) iniciativas/atividades/estratégias } \\
\text { adequadas às capacidades e ritmos }\end{array}$ & 24 \\
\hline $\begin{array}{l}\text { Desenvolve práticas/atividades/estratégias educativas e do ensino } \\
\text { adequadas às capacidades e aos ritmos das crianças e dos alunos }\end{array}$ & 19 \\
\hline
\end{tabular}




\begin{tabular}{|l|c|}
\hline $\begin{array}{l}\text { A oferta educativa/formativa adequada às capacidades e ritmos das } \\
\text { crianças e dos alunos }\end{array}$ & 2 \\
\hline $\begin{array}{l}\text { Desenvolve práticas de diferenciação pedagógica de forma } \\
\text { consistente/generalizada }\end{array}$ & 12 \\
\hline $\begin{array}{l}\text { Não desenvolve iniciativas/atividades que potenciem o } \\
\text { desenvolvimento das aprendizagens de alunos com capacidades } \\
\text { excecionais. }\end{array}$ & 8 \\
\hline $\begin{array}{l}\text { Desenvolve iniciativas/atividades que potenciem o } \\
\text { desenvolvimento das aprendizagens de alunos com capacidades } \\
\text { excecionais. }\end{array}$ & 1 \\
\hline
\end{tabular}

Fonte: Elaborado pelos autores.

Verificou-se que não existe associação entre a variável políticas e/ou cultura de inclusão e as variáveis classificação do domínio e diferenciação pedagógica. Porém, a análise de conteúdo mostrou que o ponto forte políticas/cultura de inclusão se relacionada com a ação do agrupamento e/ou escola não agrupada relativamente aos alunos/crianças com necessidades educativas especiais.

\section{Conclusões}

O principal objeto deste estudo foi a sobredotação. É certo, que a avaliação externa das escolas não é um programa virado para a sobredotação. Todavia, apesar da organização educativa constituir a unidade central de análise deste programa, o campo de análise Práticas Educativas que integra o domínio Prestação do Serviço Educativo, inclui referentes relacionados com práticas de diferenciação pedagógica e/ou adequação de atividades educativas e do ensino às capacidades e aos ritmos de aprendizagem das crianças e dos alunos (grifo nosso).

Do estudo realizado, verificámos que, globalmente, cada agrupamento de escolas apresenta, em média, 5,5 pontos fortes e 5 áreas de melhoria. Quer os pontos fortes, quer as áreas de melhoria estão relacionados com os três domínios em avaliação (Resultados, Prestação do Serviço Educativo e Liderança e Gestão), particularmente com os campos de análise que integram cada domínio.

Dos 59 relatórios, apenas um registava duas áreas de melhoria relacionadas com a temática em estudo, nomeadamente (i) A generalização das práticas de diferenciação pedagógica na sala de aula e (ii) a criação de dispositivos de identificação e apoio aos 
alunos com capacidades excecionais. Contudo, a partir da análise de conteúdo, verificámos que só um relatório refere explicitamente que o agrupamento promove atividades/iniciativas para os alunos/crianças com capacidades excecionais.

Responder à heterogeneidade implica promover de forma generalizada práticas de diferenciação pedagógica. No caso deste estudo, verificámos que a diferenciação pedagógica como prática abrangente e generalizada ocorre em 20,3\% das escolas/agrupamentos da amostra. Em regra, estas escolas são valoradas com a classificação de muito bom no domínio da prestação do serviço educativo. Por outro lado, se é certo que a maioria das escolas/agrupamento promove diferenciação pedagógica, também é verdade que só numa minoria este processo é sistemático, abrangente e generalizado. Ademais, da totalidade das escolas da amostra, só é seguro afirmar-se que apenas uma apresenta dispositivo educativo adequado às crianças e alunos com capacidades excecionais.

As políticas ou práticas inclusivas emergem como um ponto forte em $17 \%$ dos agrupamentos/escolas não agrupadas avaliados. Porém, com base neste estudo, concluímos que não existe uma correlação estatisticamente significativa entre as práticas/políticas inclusivas e a diferenciação pedagógica. Esta conclusão, aparentemente estranha, deve-se ao facto deste constructo ter sido perspetivado, a nosso ver, num sentido restritivo/redutor. $\mathrm{Na}$ realidade, a utilização deste conceito com enfoque principalmente nas crianças e alunos com necessidades educativas especiais de caráter permanente leva a que as instituições educativas com um trabalho meritório no âmbito da educação especial sejam consideradas como inclusivas. Neste sentido, os resultados obtidos neste trabalho corroboram a ideia de Ainscow (2009, p.15) que afirma que "[...] há uma suposição comum de que inclusão é principalmente acerca de educação de estudantes com deficiência, ou os classificados como portadores de necessidades educacionais especiais, nas escolas regulares”.

Porém, temos para nós como certo que uma escola só será verdadeira justa, democrática e inclusiva se desenvolver com intencionalidade processos educativos diferenciados para todos os alunos.

\section{ANSWERS OF THE SCHOOLS REGARDING HIGHLY GIFTED STUDENTS OR STUDENTS WITH EXCEPTIONAL CAPABILITIES. A BRIEF GLANCE OVER THE VIEW OF EXTERNAL ASSESSORS}


ABSTRACT: In the school year of 2012-2013, the General Inspection for Education and Science (Inspeção-Geral de Educação e Ciência - IGEC) proceeded with the program of External Assessment of Schools which led to the assessment of 122 grouped schools and 22 non grouped schools. After the assessment, a report is produced for each educational unit and it is publicized on the web page of IGEC. In each report, the assessment team makes an appreciation on the functioning of the educational unit. This appreciation is focused on nine analysis fields. These fields are integrated in three ranges (Results; Implementation of the Educational Task; Leadership and Management). Each range is classified according to a five level scale (excellent, very good, good, sufficient and insufficient). The last section of each report highlights the best achieved features as well as the ones that need to be improved. In order to comprehend the principal educational means available in both grouped and nongrouped schools as well as the quality and nature of the educational responses applied to highly gifted students, the content of 59 reports was analysed. According to the data we gathered, we concluded that there is only a reduced number of schools that present appropriate pedagogical responses for highly gifted students and that there is still a long path to go till a school can fairly be considered an including organization.

KEYWORDS: Giftedness. Students with exceptional capabilities. Inclusion. Pedagogical differentiation. External assessment of schools.

\section{REFERÊNCIAS}

ACEREDA, A.; SASTRE, S. La superdotación: personalidad, evaluación y tratamiento psicológico. Madrid: Síntesis, 1998.

AINSCOW, M. Tornar a educação inclusiva: como essa tarefa deve ser conceituada. FÁVERO, O. et al. (Org.). Tornar a educação inclusiva. Brasília: UNESCO/ANPED, 2009. p.11-23.

BELL, J. Como realizar um projeto de investigação. 3.ed. Lisboa: Gradiva, 1993.

CASTELLÓ, A.; GENOVARD, C. El límite superior: aspectos psicopedagógicos de la excepcional intelectual. Madrid: Pirámide, 1999.

FALCÃO, I. C. Crianças sobredotadas: que sucesso escolar? Rio Tinto: Edições ASA, 1992.

GAGNÉ, F. Giftedness and talent: reexamining a reexamination of the definitions.

Gifted Child Quarterly, [S.1.], v.29, n.3, p.103-112, 1985.

. Transforming gifts into talents: the DMGT as a developmental theory. High

Ability Studies, [S.1.], v.15, n.2, p.119-147, 2004.

; GUENTHER, Z. O DMGT 2.0 de Françoys Gagné: construindo talentos a partir da dotação. Sobredotação, ANEIS, Portugal, n.11, p.7-23, 2010.

GARDNER, H. Frames of mind: the theory of multiple intelligences. New York: Basic Books, 1983. 
Intelligence reframed: multiple intelligences for the 21st Century. New York: Basic Books, 1999.

JOHNSEN, S. K. Identifying gifted students: a practical guide. Waco: Prufrock Press, Inc., 2004.

KIRK, S. A.; GALLAGHER, J. J. Educação da criança excepcional. São Paulo: Martins Fontes, 2000.

MAKER, C. J.; NIELSON, A. B. Teaching models in education of the gifted. Austin: Pro-Ed, 1995.

MCCOACH, B. D.; O’ CONNELL, A. A.; LEVITT, H. Ability grouping across kindergarten using an early childhood longitudinal study. Journal of Educational Research, [S.1.], v.99, n.6, p.339-346, 2006.

MÖNKS, F. J. De rol van de sociale omgeving in de ontwikkeling van het hooghegaafde kind. Amersfoort: ACCO, 1988.

. Development of gifted children: the issue of identification and programming. In: MÖNKS, F. J.; PETERS, W. (Ed.), Talent for the future. Assen: Van Gorcum,1992. p.191-201.

NOVAES, M. H. Desenvolvimento psicológico do superdotado. São Paulo: Editora Atlas, S.A., 1979.

OLIVEIRA, E. P. Alunos sobredotados: a aceleração escolar como resposta educativa. 2007. 329 f. Tese (Doutorado em Psicologia) - Universidade do Minho, Braga, 2007.

PORTUGAL. Constituição (1976). Constituição da República Portuguesa. Coimbra: Assembleia Constituinte, 1976.

. Decreto-lei n.3/2008, de 7 de janeiro. Diário da República, $1^{a}$ série, n. 4/2008. Lisboa: Ministério da Educação, 2008.

. Despacho normativo n. ${ }^{\circ}$ 24-A, de 6 de dezembro de 2012. Diário da

República, $2^{\mathrm{a}}$ série, n.236. Lisboa: Ministério da Educação, 2012.

. Despacho normativo n. ${ }^{\circ}$ 50, de 9 de novembro de 2005. Diário da República, 2a série, n.222. Lisboa: Ministério da Educação, 2011.

QUIVY, R.; CAMPENHOUDT, L. Manual de investigação em ciências sociais. 3.ed. Lisboa: Gradiva, 2003.

RENZULLI, J. S. The three-ring conception of giftedness: a developmental model for creative productivity. In: STERNBERG, R. J.; DAVIDSON, J. E. (Ed.). Conceptions of giftedness. New York: Cambridge University Press, 1986. p.53-92.

; REIS, S. M. Que es el enriquecimiento escolar? Como se relacionan los programas para superdotados con la mejora escolar total? In: ALONSO BRAVO, J. A.; RENZULLI, J. S.; MATE, Y. B. (Ed.). Manual international de superdotacion. Madrid: EOS, 2003. p.243-257. 
SCHIEVER, S. W.; MAKER, C. J. Enrichment and acceleration: an overview and new directions. In: COLANGELO, N; DAVIS, G. A. (Ed.). Handbook of gifted education. 2.ed. Boston: Allyn and Bacon, 1997. p.113-125.

SERRA, H. Projecto sábados diferentes: um programa de apoio ao desenvolvimento pessoal e social de crianças sobredotadas. In: ALMEIDA, L. S. et al. (Org.). Alunos sobredotados: contributos para a sua identificação e apoio. Braga: ANEIS, 2000. p.149-154.

SOUTHERN, W. T.; JONES, E. D.; STANLEY, J. C. Acceleration and enrichment: the context and development of program options. In: HELLER, A.; MÖNKS, F. J.; PASSOW, A. H. (Ed.). International handbook of research and development of giftedness and talent. Oxford: Pergamon, 1993. p.387-409.

STERNBERG, R. J. Beyond IQ: a triarchic theory of human intelligence. New York: Cambridge University Press, 1985.

TUCKMAN, B. Manual de investigação em educação: como conceber e realizar o processo de investigação em educação. 2.ed. Lisboa: Fundação Calouste Gulbenkian, 2002.

UNESCO. Conferência Mundial de Educação para Todos. Declaração mundial sobre educação para todos e Plano de ação para satisfazer as necessidades básicas de aprendizagem. Jomtien: WCEFA, 1990.

The open file on inclusive education. Paris: UNESCO, 2001.

WINNER, E. Crianças sobredotadas: mitos e realidades. Lisboa: Horizontes Pedagógicos, Instituto Piaget, 1999. 